\title{
MATHEMATIC FORMULAS FOR CALCULATING THE PRICES FOR SELLING AND BUYING ELECTRIC ENERGY IN BULGARIA
}

\author{
S. Boneva* \\ Faculty of International Economy and Polic, University of National and World Economy, \\ Sofia, Bulgaria
}

\begin{abstract}
The paper presents the mechanism for determination of the prices at which the electricity Suppliers of last resort (EVN, CEZ and Energo-pro) buy electricity from the National electric company (NEC) and then sell it to final consumers. The Rules for trade with electrical energy (RTEE) in Bulgaria; the role of the Public energy supplier (the National Electric company) in determining energy prices and the roles of the State Energy and Water Regulatory Commission (SEWRC) in determining the forecasted quantities of electric energy that are subject of compulsory purchase as well as in determining the quantities that are not subject of compulsory purchase within the limits of the availability determined according to the Bulgarian Energy Act have been outlined in the research. The mathematic formulas used by SEWRC in determining energy prices and a method for determining of the non-balances between the members of the Special balancing group of one of the Suppliers of last resort in Bulgaria have been presented.
\end{abstract}

Keywords: electricity pricing , methods for calculation of electricity prices, rules for trading with electricity

Mathematic formulas for determination of the prices of electric energy of Suppliers of last resort $(\mathrm{SLR})^{1}$ are proposed by the State Energy and Water Regulatory Commission (SEWRC) in a special Methodology, adopted with decision as per point 2 of Protocol №110/18.07.2013 of SCEWR, based on art. 21, paragraph 1, point 12 of the Energy act ${ }^{2}$.

*Correspondence to: Assoc. prof. Svetla Boneva, Ph. D, University of National and World Economy - Sofia, Faculty of International Economy and Policy, svetla_bogdanova@yahoo.com

Methodology regulates the way of determination of prices used by the Suppliers of last resort to purchase and sell electric

\footnotetext{
${ }^{1}$ Art. 104 (1) (Canget-State Gazette, N 99, 2914) Suppler of Last Resort is a company that holds a license according to the Energy Act to provide electricity:

when a Main Supplier which is a party of a contract for energy supply is no more able to continue to provide energy due to insolvency, suspension of a license or other event, leading to temporary or constant stopping of the supply of electricity;

for end clients that cannot be clients of the End Supplier till the choice of another suppler.

${ }^{2}$ The Energy Act, promulgated for the first time in State Gazette Nr. 107 of 9.12.2003, has undergone many changes till today. The methodology that has been explained is introduced in its change of 5.07.2013.
}

energy to end-users that on the free market until the moment in which they will choose another supplier based on market principle as well as in the cases when they have been on the free market, but they have remained without a supplier of electric energy.

The Rules for trading with electric energy $(\mathrm{RTEE})^{3}$ arrange the relations among customers and the Supplier of last resort. These relations are expressed in contracts with publicly known general terms in compliance with the Energy act.

When determining the prices of electric energy of a Supplier of last resort (SLR) the following rules should be followed:

- SLR is signing contracts for electric energy with the Public supplier ${ }^{4}$. The Public supplier (in this case NEC) is forming the quantities of electric energy for obligatory

\footnotetext{
${ }^{3}$ The Rules for trading with electric energy adopted by the SEWRC and promulgated in State Gazette, arrange the relations between the customers and electricity suppliers.

${ }^{4}$ As a Public Supplier of electricity in Bulgaria NEC AD (the National Electricity Company Ltd.) is the only supplier of electricity at regulated prices for the four energy-distributing companies of medium and low voltage in Bulgaria as well as for about 90 industrial companies that are associated to the electricity network.
} 
purchase, as per art. 93a of the Energy act. as well as the forecasted quantities with freely negotiated prices.

- $\quad$ SEWRC determine in a decision the forecasted quantities of electric energy for obligatory purchase as per art. 93a of the Energy act that are needed for provision of coverage of the consumption by the customers of SLR as well as the forecasted quantities of energy that are not subject of obligatory purchase from condensation plants within the availability determined based on art. 21, par.1, point 21 from the Energy act.

The calculation of the average purchase price of electric energy, purchased by Supplier of last resort is done according to the following formula:(1), (2), (3):

$$
P_{S L R / \text { purc }}=P_{\mathrm{e} n}+P_{p s}
$$

where:

$P_{S L R} /$ purc - price of electric energy purchased from SLR, leva/MWh;

$P_{\text {en }}$-price of energy, lv./MWh;

$P_{p s}$-price for the "activity public supply", lv./MWh.

The price of energy for SLR is calculated using the formula:

$$
P_{\mathrm{e} n}=\frac{C_{\mathrm{e} n}}{\mathrm{E}_{\mathrm{e} n}}
$$

where:

$C_{\mathrm{eH}}-$ costs for purchased electric energy from SLR, in thousands of lv;

$\mathrm{E}_{\mathrm{eH}}$ - total purchased electric energy from SLR, in MWh.

The costs of SLR for the purchased energy are calculated using the formula (3):

$$
\underset{O}{C_{e n}}=\left(\sum \mathrm{E}_{1} \cdot P_{1}+\mathrm{E}_{2} \cdot P_{2}+\cdots+\mathrm{E}_{2} \cdot P_{n}\right)-
$$

where:

$E_{1 . . n^{-}}$quantities of purchased electric energy from SLR, including quantities, subject to obligatory purchase as per art. 93a and the quantities of energy that are not subject to obligatory purchase from condensation power stations within the limits for availability determined by art. 21, par. 1, point 1 of the EA.

$P_{1 . n^{-}}$price of electric energy at which SLR is buying the quantities electric energy;

$\mathrm{O}$ - revenues from the price for "obligations to society", ${ }^{\prime \prime}$ that is paid by the customer to

\footnotetext{
${ }^{5}$ The costs for purchase of electric energy resulting from obligations to society are included in the price of electric energy at which the Public supplier is selling electric energy to End suppliers for the 264 balancing energy, in force since 26.07.2013, published SG. Issue 66 dated 26 July 2013, amended and suppl. SG. Issue 39 dated $9^{\text {th }}$ May 2014.

traders on the free market, for the quantities of energy for internal consumption.

In the costs for purchased energy the costs for purchase of balancing energy ${ }^{6}$, are included, as per Rules for trading with electric energy. When given SLR of electric energy has not succeeded to make precise forecasts for the energy needed it appears that he has requested more or less energy. Namely this difference from the exactly needed energy is called balancing energy (in excess or shortage). The prices of balancing energy are determined administratively. The energy in excess is sold at much lower prices compared to the average price of electric energy, while the energy in shortage is purchased at much higher price compared to the average price of electric energy. This is done with the aim all participants in the trading with electricity to strive to make precise forecasts of their consumption and in this way not to spent unnecessary resources for its production. The balancing energy is controlled by NEC.

The formation of the price of the balancing energy $^{7}$ is still done administratively. By that way the effect of market forces is not allowed and there is no competition in formation of the price of the balancing energy. The changes in the formation of the price of the balancing energy that were introduced in July 2013 are correcting a wrong policy. These are a step in the right direction, but are not enough to stimulate the market development. Coordinated changes of the Rules for trading and the Rules for management of the electric energy sector (EES) in relation to proposal and utilization of operational tertiary reserve of EES.

The average sales price of electric energy intended for sales from SLR to customers is calculated by the formula (4):

customers on the regulated market, to the network operators for coverage of technology costs and to Suppliers of last resort (SLR). These costs of the Public supplier for the purchased electric energy for each pricing period are determined by SEWRC on the basis of forecasted annual production according to the quantities and costs for each type of electricity generation determined by a decision of the Commission.

${ }^{6}$ Stefanov S., V. Ruseva, Analysis of the pries of electricity energy in Bulgaria, proceedings of Russe University, 2012, Vol, 51, Ser. 3.1

${ }^{7}$ Methodology for determination of prices of 


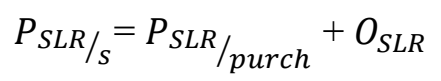

where:

$P_{S L R} /$ purch - average purchase price of electric energy, purchased by SLR, lv./MWh;

$\mathrm{O}_{\text {SLR }}$ - overcharge for the activity ,supplier of last resort", lv./MWh.

SLR can propose different tariff structures ${ }^{8}$ to his customers.

The average sales price of the electric energy supplied by SLR include overcharge $(H)$ up to $3 \%$ from actually incurred costs for purchase of electrical energy.

The main obligations of SLR are:
- To prepare schedules for customers that are not able or do not want to submit daily electrical load schedule;

- To determine the average purchase price by formula (1) not later than 5 working days before the date of its application;

- To collect from their customers the funds for the value of the network services, approved by SCEWR for the given period;

- $\quad$ For the purposes of subsequent control the SLR is submitting to SCEWR the methodology for calculation of prices and tariffs in compliance with the methodology of SCEWR for determination of prices.

Every SLR, called also Coordinator ${ }^{9}$ develops his own "General principles for distribution of imbalances in his Special balancing group (SBG)10 in compliance with the requirements of art. 58, paragraph 2, point 2 of RTEE.

\footnotetext{
Text Box ${ }^{11}$

(2) Participants in the business are having the right to register themselves as "coordinators of special balancing groups" if they have fulfilled the following conditions:

1. have license for production, transmission, distribution, organization of commodity exchange, public supply, supply from end supplier, supply from SLR of electric energy and distribution of pulling electric energy as per art. 39, paragraph 1, points $1,2,3,6,7,10,12$, and 13 3E;

2. have developed "general principles for distribution of non-balances within the special balancing group" and have published them in their internet web page;

3. (amendment - SG, issue. 39 from 2014) decision for addition to existing license of rights and obligations related to activity of "coordinator of special balancing group", as per art. 39 , paragraph 5 of EA;

4. the requirements are fulfilled and communication equipment and information exchange facilities are maintained according to these rules;

5. there are no obligations towards public supplier, end suppliers, the independent transmission operator and operators of electro-distribution networks.
}

The principles for distribution of nonbalances in the Special balancing group of SLR contain the General conditions and rules for calculation and distribution of nonbalances and costs for them among members of the balancing group.

The costs for non-balances in the special balancing group of "ENERGO-PRO Sales" $\mathrm{AD}$ are added to the costs for purchasing of

\footnotetext{
${ }^{8}$ The tariff structure gives an idea for the prices of the electric energy sold from SLR to his customers during all periods of the day and night, during which are determined one, two (daily and night tariff) and three (top, daily and night) tariff scale for the electric energy. SLR are choosing by themselves the tariff scales by which to sell the electric energy.

${ }^{9}$ Coordinator of the balancing group is a person that according to his license bear responsibility before
}

electric energy when the price of the electric energy is determined as per "Methodology for determination of the prices of electric energy of SLR" of SEWRC, and „Methodology for determination of tariffs and prices of electric energy of ENERGOPRO Sales" AD in their capacity of supplier of last resort.

ESO/NEC for non-balance of their balancing group and re-distribute this non-balance among their members.

${ }^{10}$ The balancing group of the End supplier is one of the special balancing groups. „End supplier” is energy company, that is buying electric energy from renewable energy sources of electric energy and heating energy. 
"ENERGO-PRO Sales" Ltd. is developing the Method for distribution of resort, based on the principles of equality among participants, proportional distribution depending on the volume of consumption of different members of the special balancing group, transparency and accessibility.

The method ${ }^{12}$ for distribution of nonbalances between the members of the Special Balance Group of "ENERGO-PRO Sales" Ltd. Adheres to the following algorithm:

1. Calculation of costs for non-balances in the Special balancing group of "ENERGO-PRO Sales" AD.

The coordinator is registering in the Energy System Operator (ESO) ${ }^{13}$ aggregated hourly schedule with forecast for consumption of all members of the special balancing group. After receipt of the reporting data and the monthly settlement ${ }^{14}$ of the Special balancing group of SLR from ESO, the Coordinator is calculating the costs for the total monthly negative/positive non-balance (shortage/surplus) of the Balancing group ${ }^{15}$ (BG) using the formula (5):

$$
C_{b a l}=C_{s}+C_{s h}
$$

where:

$\mathrm{C}_{\text {bal }}$ - actual costs of "ENERGO-PRO Sales" $\mathrm{AD}$ in their role of SLR for the relevant reporting period, lv;

$\mathrm{C}_{\mathrm{s}}$ - the amount of costs, resulting from hourly positions in surplus of the special balancing group of "ENERGO-PRO Sales" AD in their role of SLR for the relevant reporting period, lv;

$\mathrm{C}_{\mathrm{sh}}$ - the amount of costs resulting from hourly positions in shortage of the special balancing group of "ENERGO-PRO Sales" AD in their role of SLR for the relevant reporting period, lv;

2. Distribution of costs for nonbalances in the Special balancing group of "ENERGO-PRO Sales" AD is following the algorithm:

2.1. Calculation of average price for nonbalances using the formula (6):

$$
P_{\mathrm{bal}}=\frac{C_{b a l}}{\mathrm{E}}
$$

where:

$P_{\text {bal }}-$ average price for balancing energy in the Balancing group of "ENERGO-PRO Sales" $\mathrm{AD}$ in their role as SLR for the relevant reporting period, lv/MWh;

E - actual consumed and measured through appliances for commercial measurement (ACM) quantity electric energy for the relevant reporting period from clients of "ENERGOPRO Sales" AD in their role of SLR.

2.2. Each member of the special balancing group of "ENERGO-PRO Sales" AD in their role of SLR is paying the part of the costs for balancing corresponding to their individual contribution to the formation of total quantities of the group through the their price of electric energy using the formula (7):

$$
P_{S L R / a v}=\mathrm{P}_{\mathrm{NEKs}}+P_{\mathrm{bal}}+\mathrm{O}_{\mathrm{SLR}}
$$

where,

$P_{S L R / a v}$ - average sales price of SLR as per which "ENERGO-PRO Sales" AD in their role of SLR is selling electric energy for the relevant reporting period, lv/MWh;

$\mathrm{P}_{\mathrm{NEKs}}-$ average price as per which "ENERGO-PRO Sales" AD in their role of SLR, is buying electric energy from the public supplier, announced by NEC for the relevant reporting period, lv./MWh;

$\mathrm{O}_{\mathrm{SLR}}$ - overcharge for the activity "supplier of last resort".

\begin{abstract}
${ }^{11}$ Rules for trading with electric energy, SG, issue 66 dated 26 June 2013, am ended and suppl. SG issue 39 dated $9^{\text {th }}$ May 2014

${ }^{12}$ General principles for determination of the nonbalances in the special balancing group of "ENERGO-PRO Sales" AD in his role of a SLR are valid for all members of the group until publishing of an updated version or until occurrence of considerable market and/or regulatory changes.

${ }^{13}$ ESO ЕАД is having a license for transfer of electric energy, including coordination of special balancing groups for the period of 35 years, issued in December 2013. The company is administering the balancing market of electricity that started on $1^{\text {st }}$ of June 2014, organizes tenders for transfer capacity and maintains centralized operational management of the national electricity system.

14 "Settlement / Non-balance" is a system for determination of the value of the difference between forecasted and measured loading profile at prices of the balancing market using methodology determined with RTEE and applied from ESO to each coordinator.

${ }^{15}$ Balancing Group (BG) - it is registered by ESO. It is established with the aim to aggregate nonbalances of the business participants in the group and softening of the economic consequences from the prices of the balancing energy. The balancing groups are standard, combined and special balancing groups, as well as virtual trade balancing group of the public supplier (NEC), towards which ESO applies equal principles for balancing. The balancing group of Last suppliers is one of the special balancing groups.
\end{abstract}

\section{CONCLUSION}

In conclusion it can be said, that Methodology for determination of prices of electric energy 
for buying and selling from SLR proposed by SEWRC, as well as the Methodology of "ENERGO-PRO Sales" AD for distribution of non-balances in the Special balancing group of SLR will contribute for determination of real prices of electric energy which is extremely important for all participants downstream from producers of electricity to end users.

Adhering to the general principles for determination of the non-balances in Special Balance Groups and SLR will help for determination of always actual prices, consistent with the costs made and income received from SLR, which will result in improvement of the condition of the electric energy sector of the country as a whole.

\section{REFERENCES}

1. Stefanov S., V. Ruseva, Analysis of the pries of electricity energy in Bulgaria, proceedings of Ruse University, 2012, Vol, 51, Ser. 3.1

2. Methodology for determination of prices of balancing energy, in force since 26.07.2013, published SG. Issue 66 dated 26 July 2013, amended and suppl. SG. Issue 39 dated $9^{\text {th }}$ May 2014.

3. Prices of electricity of E-ON Bulgaria, www.eon-bulgaria.com

4. www.evn.at

5. Strom-Report: Electricity prices in Europe, http://strom-

report.de/strompreise/\#strompreise-europa 